\title{
The Potential of ICT SMEs In Pakistan
}

\author{
Sadaf Mustafa \\ Assistant Professor, \\ Department of Commerce, University of Karachi \\ Muhammad Arshad \\ Faculty Member, \\ Department of Commerce, University of Karachi
}

Nighat Moin

Assistant Professor, Faculty of Management Sciences, Indus University, Karachi.

\begin{abstract}
Pakistan has been registering increasing growth rates in its Information Communication and Technology (ICT) sector, with IT exports crossing $\$ 2.5$ billion mark and registered IT companies surpassing 2000 in number. The growth is mainly powered by service-sector small and medium enterprises (SMEs) of the country, which are subject to little or no regulatory requirements and a lucrative tax amnesty up to June 2019. The information and communication technologies (ICT) sector of Pakistan employs thousands of micro and small firms and self-employed individuals producing various ICT related products and services for domestic and foreign consumption. These small business units may comprise of just an individual, a group of individuals, micro enterprises up to 10 employees and medium sized companies up to 200 employees. The present paper seeks to present, first, the heterogeneous nature of the sector, classifying and comparing enterprises working in it against the prevalent definitions of SMEs. Next, the size and of this SME subset is identified in terms of its consumers, producers, business units and business volumes, with a particular focus on how these together stimulate the economy of the country through increased ICT-based consumption, employment and exports. The paper then analyses some of the challenges and limitations faced by small ICT firms of Pakistan and evaluates whether appropriate measures and initiatives are reflected by ICT and SME stakeholders of Pakistan such as Pakistan Software Exports Board, Pakistan Telecommunications Authority, and SME Development Authority,. The research is exploratory and descriptive in nature. Extensive literature is sought from reputed journals, books, surveys, reports, publications and authoritative web sources targeting service-sector SMEs. The findings of this research hint at major areas of concern and improvement in ICT-based SMEs of Pakistan. They offer great significance for owners, partners, workers and individuals of ICT SMEs as well as government authorities, policymakers and academicians aspiring to strengthen the SME sector.
\end{abstract}

Keywords: IT-based SMEs of Pakistan, IT sector of Pakistan, ICT SMEs

\section{INTRODUCTION}

The knowledge-based revolution led by information and communication technologies (ICT) is fast altering the economies of developing countries. Several emerging economies have taken on the ICT path to alleviate poverty, increase exports and boost employment (Mukras, 2003). ICTenabled services and applications allow room for expansion for tech firms even when they cannot find local market (Iftikhar, 2017). Exponential growth in use of internet and mobile phone in India, Sri Lanka and Pakistan, for example, has created a greater room and demand for IT-enabled services such as e-commerce, freelancing and digital marketing 
(Dasanayaka,2010). Moreover, the latency presented by many traditional large-scale firms in adopting IT services has given many small-scale firms to fill up the void by offering mobile and web applications easing the use of conventional products and services.

The tech-startup world manifests hundreds of thousands of freelancers offering several web and mobile services to offshore clients, offering services ranging from web design and development to social and search engine marketing (Ahmed, Shahzad \& Umar, 2010). Hence, governments in developing countries are fast facilitating an enabling ICT environment through policy initiatives such as provision and development of technical training centers, mega IT parks, and co-working spaces and incubators.

ICT enterprises of Pakistan, besides forming part of the SME sector, are also a subset of 'Knowledge Economy'. It is described as a mix of interrelated components such as IT goods and services, information content, telecommunications, networking, transmission, offline multimedia, and online trading interactive. The dynamic ecosystem and infrastructure of the sector is presented in a model presented by D'Costa (2006).

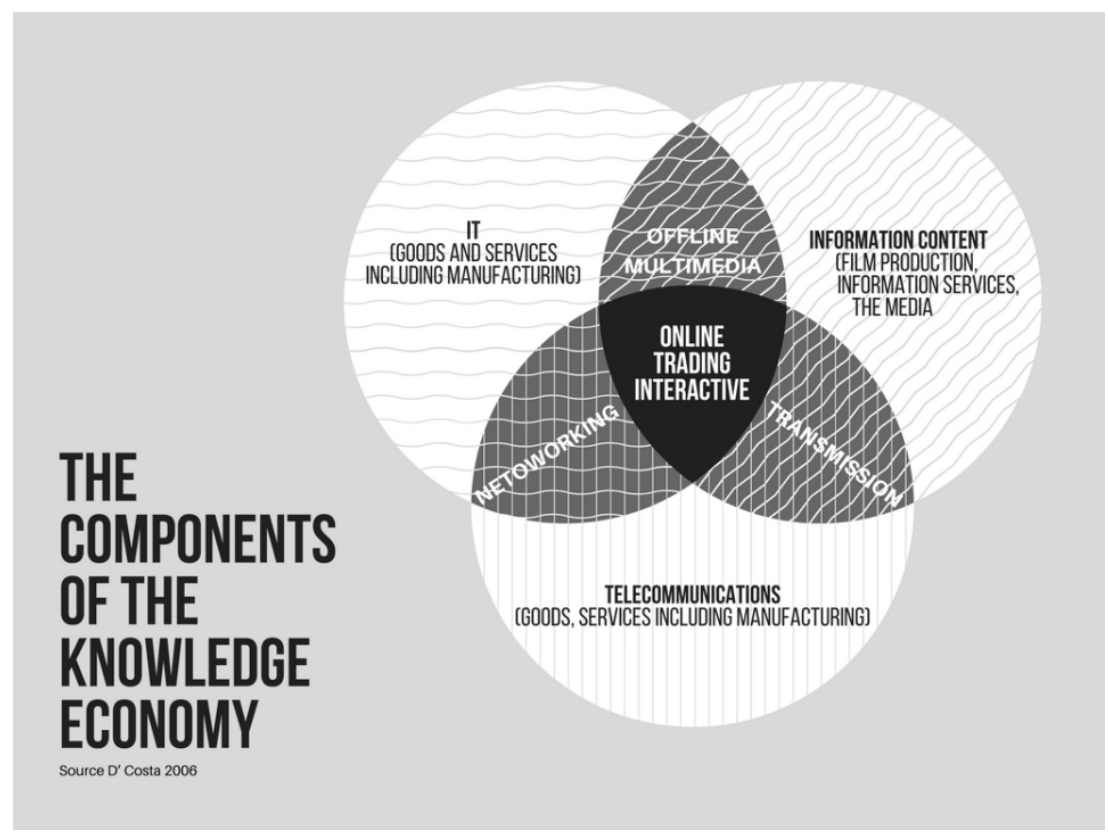

Source: D'Costa, 2006

Since SMEs operate in a widely heterogeneous business environment, there is no universally agreed criterion to classify a business as an SME. Different countries have set different benchmarks for identifying businesses as 'SMEs' for statistical and legal purposes. Common in such benchmarks include revenue, number of employees, output and valuation of assets (Cunningham and Rowley, 2008). For the purpose of this research, however, we take in all ICT enterprises (whether big or small), freelance houses and incubators as well as tech start-ups relying on collaborative 'project-based' services rather than full-time workers for carrying out their operations.

Pakistan's ICT sector, mainly driven by SMEs, can be used to tap enormous economic potential through increase in the country's employment levels, exports, consumption and foreign direct investment. According to Mujahid (2001), Pakistan has been fast working to improve its ereadiness to achieve its macroeconomic goals through the contribution of the ICT sector. 


\section{Research Aims and Objectives}

1. To identify the different definitions for SMEs and assess which one fits best based on Pakistan's socio-economic and business scenario.

2. To assess the extent and size of the small-sized IT enterprises of Pakistan, or ICT SMEs sector, measuring this sub-sector's business and consumer volume.

3. To assess the potential for employment, local consumption and exports of Pakistan's ICT SME sector.

4. To evaluate the present policy initiatives taken to facilitate and grow the ICT SME sector.

\section{DISCUSSION}

The importance of Small and Medium Enterprises (SMEs) as catalysts for economic growth, employment and poverty reduction has been widely established. SME firms are generally more labor intensive than capital intensive, and present a higher return on investment than many large-scale enterprises. According to Cunningham and Rowley (2008), the dynamic nature of SMEs allow them to quickly adjust to changing business conditions which makes the SME sector as an 'agent' of positive socio-economic change. Governments, especially those of developing nations, have recognized this fact, and are quickly formulating policies to foster and boost their SME sectors (Feeny \& Riding, 1997).

Researchers have also extensively shown interest in gauging the effectiveness of governmental support to the SME sector (Kwarteng et al, 2016). According to Rahman, Stough \&Jalees (2015), SME sector's contribution is heavily dependent on the support systems and policies provided by the government. The findings of their research stress on the need for the policies to target all three areas of an SME business cycle: introduction, growth and operation.

The main aim of the SMEs is the creation of jobs, and their major contribution can also be measured in the same sense (Tsai et al. 2007). Because of their informality and heterogeneous nature, we cannot asses their impact on the macroeconomic level and most of the studies only emphasize on their potential of job creation (Dar, Ahmed and Raziq 2017).

As concluded by Dearden (1998) the SMEs are too small to influence at the macro level, they are highly individualized enterprises comprise of a highly individual composition, nature and style of working. Hence, they cannot give back to economy at a macro level. Therefore, the Small and Medium sized entrepreneurs (SMEs) generally run at the possibility of sustainability and job creation .so they usually have low productivity and instability. The poor working conditions, low safety standards and inadequate training facilities further add into the misery of SMEs, as these factors are not in focus for empirical testing (Tsai et al. 2007).

The studies in the past have indicated some trends in the behavior of operation if these SMEs, but there is no standardization in the working pattern, which creates difficulties in giving a uniform pattern to streamline the working of SMEs. SMEs have a far greater flexibility in their nature of operations compared to large organizations.

It is fact that these organizations have a tight control and close monitoring of the operations (Tsai et al. 2007). But, at the same time they also lack in resource as well as the skills and time constraints are also present. Due to this, these organizations often face limited growth, reactive and adhoc approach towards situations and inconsistent working hours. 


\section{Definition and Characteristics}

In Pakistan, variable definitions have been given by Small and Medium Enterprises Development Authority (SMEDA), Small and Medium Enterprises (SME) Bank, State Bank of Pakistan (SBP), Securities and Exchange Commission of Pakistan (SECP) and Pakistan Bureau of Statistics (PBS). SMEDA's definition of SME is based on amount of productive assets and number of employees; the SME bank considers only the amount of production assets, PBS considers only number of employees (Dar, Ahmed and Raziq 2017).

The generally agreed definition is that of SMEDA, which considers a business as small when its number of employees range between 10 and 35 and its production assets are in the volume of 2 to 20 million PKR. Similarly, the definition for medium-sized business is that it has to have between 36 to 99 employees and a production assets volume 20 to 40 million PKR (SMEDA, 2011).

The above definitions, however, do not take into account size and volume of micro businesses, the employee base and assets volume of which might be lower than those stated by SMEDA. Dar, Ahmed and Raziq (2017) have therefore proposed a new definition for small businesses, which takes in number of employee size between 5 and 10 and production assets size between 0.5 and 1 million PKR.

The United Nations Industrial Development Organization (UNIDO) classifies SMEs based on whether to belong to developing countries or the developing ones. In the table below, classification for SMEs belonging to developed and developing nations are presented as observed by UNIDO (Abor and Quarty, 2010).

\begin{tabular}{|c|c|c|c|}
\hline Developing Nations & Employee Size & Developed Nations & Employee Size \\
\hline Micro Firms & $<5$ & Small Firms & $<99$ \\
\hline Small Firms & $5-19$ & Medium Firms & $100-500$ \\
\hline Medium Firms & $20-99$ & Large Firms & $>500$ \\
\hline Large Firms & 100 & & \\
\hline
\end{tabular}

Source: The United Nations Industrial Development Organization (UNIDO)

In a study by Wadood, Shamsuddin \& Abdullah (2013) the characteristics of innovative SMEs, particularly those working as SMEs were investigated. The findings hints at efficacy of certain characteristics and standards meant specifically for the policy makers. The study investigated all the different categories of innovation (Process, Product, Organization and Marketing) for the targeted sector, and tried to assess the quantum of innovative activities in these firms. The focus was on process innovation, as it was regarded as the top most priority of any ICT firm. The innovation was found as the main focus in the organization structure and depended heavily on the number of professionals and the financial position of the firm (Wadood, Shamsuddin \& Abdullah, 2013).

\section{The Size of Pakistan ICT Industry}

Pakistan ICT industry is heavily influenced by overall media landscape of the country. By the end of 2008, Pakistan had 350 newspapers, 74 radio stations, 70 private TV channels, 1600 cable operators, 3.5 million cable subscribers and over Rs.10 billion of investment in satellite (Hamid, 2008).

Pakistan is a country where about $60 \%$ of their population is in the 15 to 29 years of age group. This shows a huge human capital. The country has more than 2000 IT companies and they are growing in numbers every year. We have a workforce of around 300,000 IT professionals who 
are experts in the ongoing and emerging IT products and at the same time good in their English speaking. The universities produce more than 20,000 IT graduates and engineers every single year. Presently, Pakistan have 14 Software technology parks (a type of IT dedicated commercial building). Pakistan's IT based exports has increased twenty times in the last ten years and stands on $\$ 2.4$ billion. In addition, the local market of free-lancing is of $\$ 100$ million in particular, and over $\$ 500$ million in general. So, the total revenue for the ICT sector is above $\$ 3$ billion. The total imports for the cellular mobile companies for the financial year 2015-16 mounting to over PKR 78.57 billion, which reflects an encouraging IT background in Pakistan.

The picture casts great potential for burgeoning ICT industry of Pakistan as most ICT SMEs base their products not for these local clients but for foreign companies and consumers.

Over the decade, the ICT sector has also shown remarkable growth. According to Pakistan Software Houses Association (PASHA), the country has a burgeoning IT industry comprising of hundreds of small to medium-sized tech firms. The current estimated size of the industry is $\$ 2$ billion, up from $\$ 1$ billion just a few years ago, with larger players making about 15-25 million dollars in yearly revenues (Pasha, 2017) and employing 12000+ employees in its 370 member software houses. The range of ICT consumers in Pakistan includes finance, communication, telecommunication and others (PASHA, 2017). The figure below shows percentage split of these consumer types.

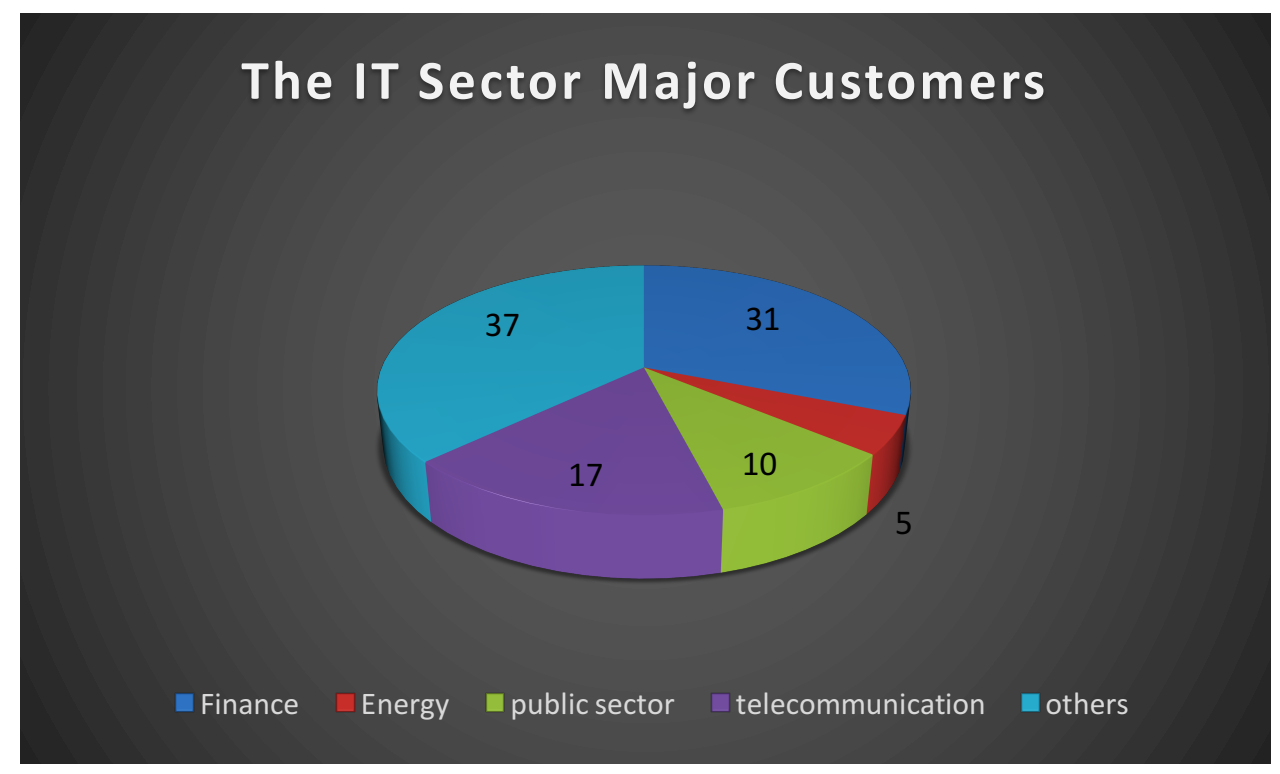

Source: Pakistan Software Houses Association

In addition to growing local operations and expansions by world's leading players like Microsoft, Cisco, and IBM, Pakistan ICT industry is fast embracing venture capital investments from firms like ePlanet, Adobe, Motorola and Innovacoml. Registering a 39\% growth of the industry during 2007-2008, PASHA estimates that the industry size will expand to 11 Billion USD mark within the next 5 years.

Besides PASHA, The Software Export Board of Pakistan (PSEB) is specifically targeted to promote the IT industry of Pakistan. Its main functions include research into Pakistan's ICT sector and development of strategies to boost its sustainable development. Besides registering IT firms in the country and creating IT parks, PSEB works in collaboration with telecom regulators governmental bodies such as PTA to track the sector's performance and suggest areas for improvement (PSEB 2017).. It has also enabled a space of about 700,000 square feet for its registered IT companies in designated IT and Software Technology Parks. In addition, PSEB facilitates services of company acquisitions and mergers, venture funds, call centers, data 
centers, training centers, incubators and gaming and animation studios. The organization has envisioned itself to boost Pakistan's IT exports from the present $\$ 2$ billion to $\$ 5$ billion level by year 2020 (PSEB 2017).

According to Pakistan Telecommunications Authority, the number of telephone, mobile and internet users have been steadily growing in the past few years. About $72 \%$ people in Pakistan have access to one of the three telecommunication services (Fixed or Landline, Wireless, and Mobile). The table below shows this teledensity for the period 2002-2017.

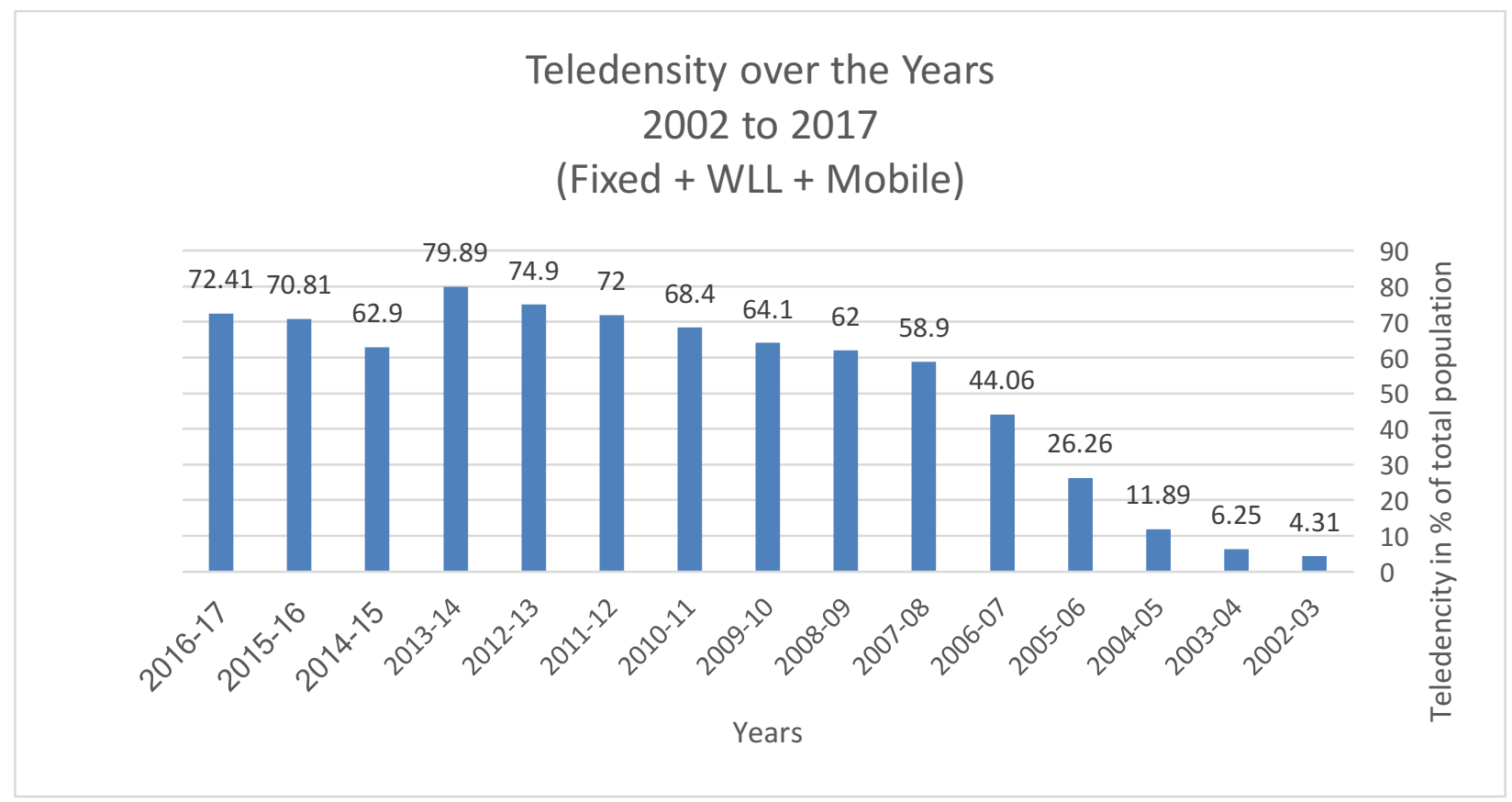

Source: Pakistan Telecommunication Authority

In these, the most rampant impact can be seen in that of mobile phone and internet users. Currently, Pakistan has about 114 million mobile phone users and 30 million internet users. This makes about 60 percent of the country's population. The vast potential and growth of in these numbers can be seen as a great consumption and revenue potential for ICT SMEs of Pakistan.

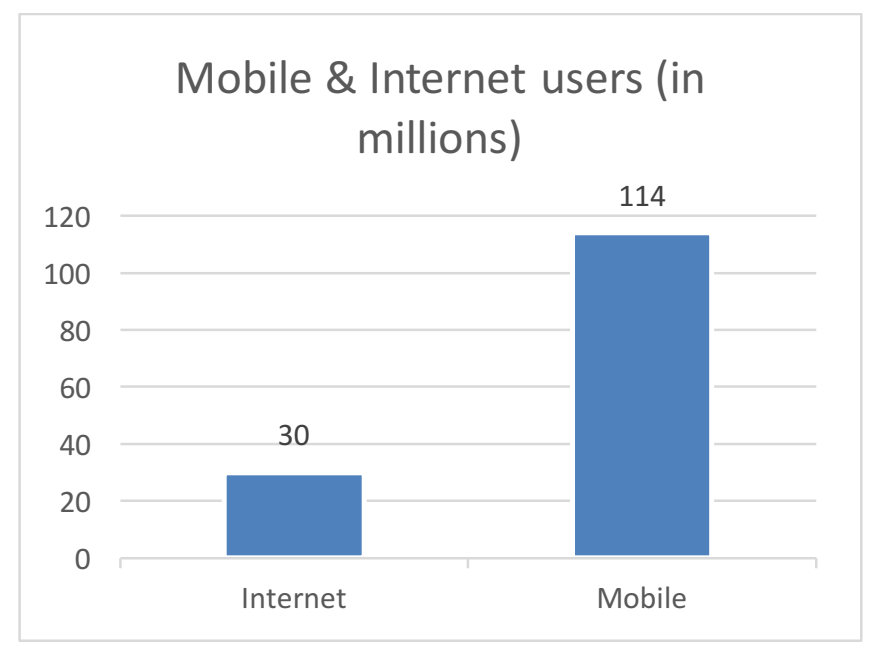

Source: Pakistan Software Houses Association 
Like the rest of the world, the number of social media users in Pakistan is also growing exponentially. The figure below shows the number of major platform social media users in millions as of August 2017.

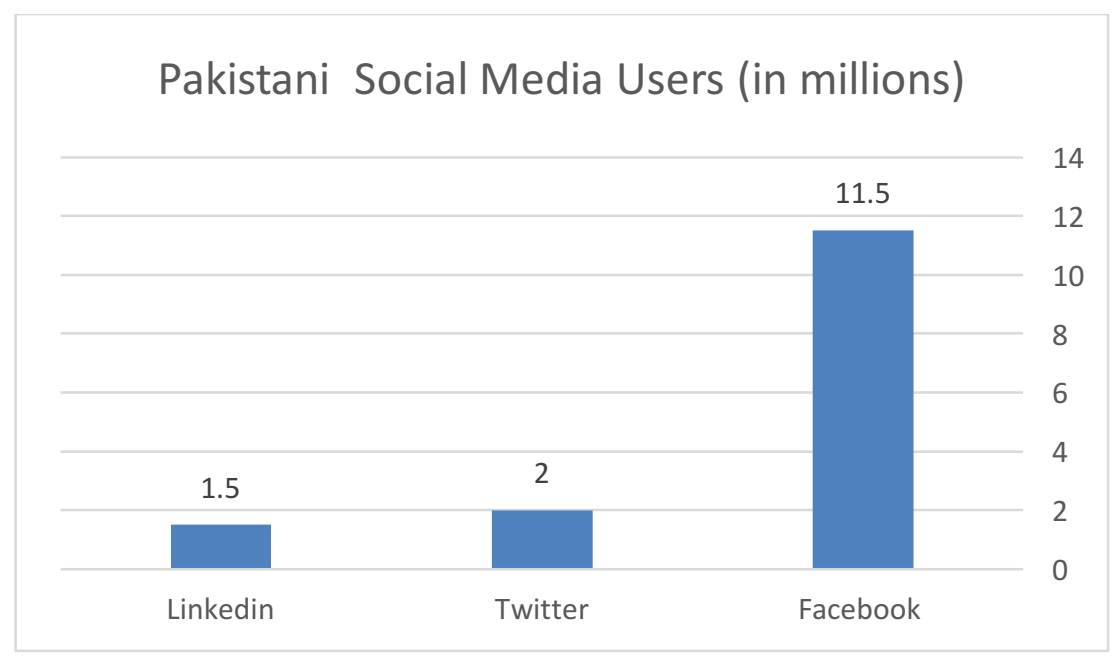

Source: Pakistan Software Houses Association

\section{Potential for Employment}

Tech-based SMEs in Pakistan are significantly accommodating college or university graduates who are increasingly finding it challenging to secure jobs in large-scale national or multinational organizations.

The ICT talent pool of the country has registered tremendous growth in recent years, with universities alone producing 10000 computer science graduates every year. However, this lags far behind the regional player India, which produces about 150,000 graduate professionals in its IT based institutions (Dasanayaka, 2010).

Adding to IT-specific university graduates of Pakistan are, however, hundreds of thousands of diploma and certificate holders from IT institutes, technical training centers and skill development organizations, as well as self-learned individual entrepreneurs. In addition to rendering services to mainstream IT companies, IT-skilled individuals and well engaged in one of the many small, IT-enabled businesses, including hardware specialists and traders, graphic and web designers, web developers, e-commerce websites, mobile app developers, software resellers, call center runners, animators, bloggers and vloggers, content writers and editors, owners and administrators of YouTube Channels, Facebook pages and social media and SMS marketers and many more.

Although countries are increasingly stressing on the economic potential of ICT-enabled services through their policies, providing tax and export relaxations, developing 'IT Parks' and establishing technical training and development centers, the isolatory nature of tech-based SMEs remains an issue (Ahmed, Shahzad \& Umar , 2010). Tech start-ups (usually SMEs) struggle to sustain businesses due to lack of adequate infrastructure, lack of local demand for IT goods and services, and lack of financing facilities from banks and DFIs.

A large part of Pakistan's ICT SME sector represents freelancing. It is a billion dollar industry subset of ICT SMEs (employing 5 people or less). Freelancing assumes various business models and formspart of a growing knowledge-based economy whereby online marketplaces exist for sales and purchase of ICT services such as content creation, graphic and web design and development, programming and digital marketing(Iftikhar, 2017). 
Currently, Pakistan ranks at 4th position for highest number of freelancers and freelance businesses, with an estimated 150000 engaged in this SME subset. Keeping in view of the employment potential of freelancing SMEs, an e-Rozgar scheme has been launched by the government of Punjab (PITB, 2017). e-Rozgar scheme is specifically aimed at reaping the freelancing potential of Pakistan. It is developing 36 training centers across various districts of Punjab and aims to train around 10,000 people in various freelancing domains (PITB, 2017). Besides promoting sustainable living for the educated youth, it also enables employment for work-at-home women thus reducing the disparities between economic and financial status of men and women. Further, the scheme is yet to add up to $\$ 1$ billion remittance of the freelance revenues of Pakistan.

\section{Potential for Local Consumption}

As of July 2017, Pakistan had about 44 million internet users, 140 million mobile phone users, and about 42 million mobile internet users (Anas, 2017). According to research conducted by Shafique \& Mahmood (2008), there were 1,898 cities with Internet access in Pakistan, of which 1,166 were situated in Punjab, 202 inSindh, 420 in KPK, and 110 in Baluchistan.

ICT SMEs can tap on the great potential of expansion in these communication facilities by developing products and services targeting market platforms (Ahmed, Shahzad \& Umar, 2010). The figure below (sourced from World Bank) shows how ICT offers market platforms for buyers and sellers.

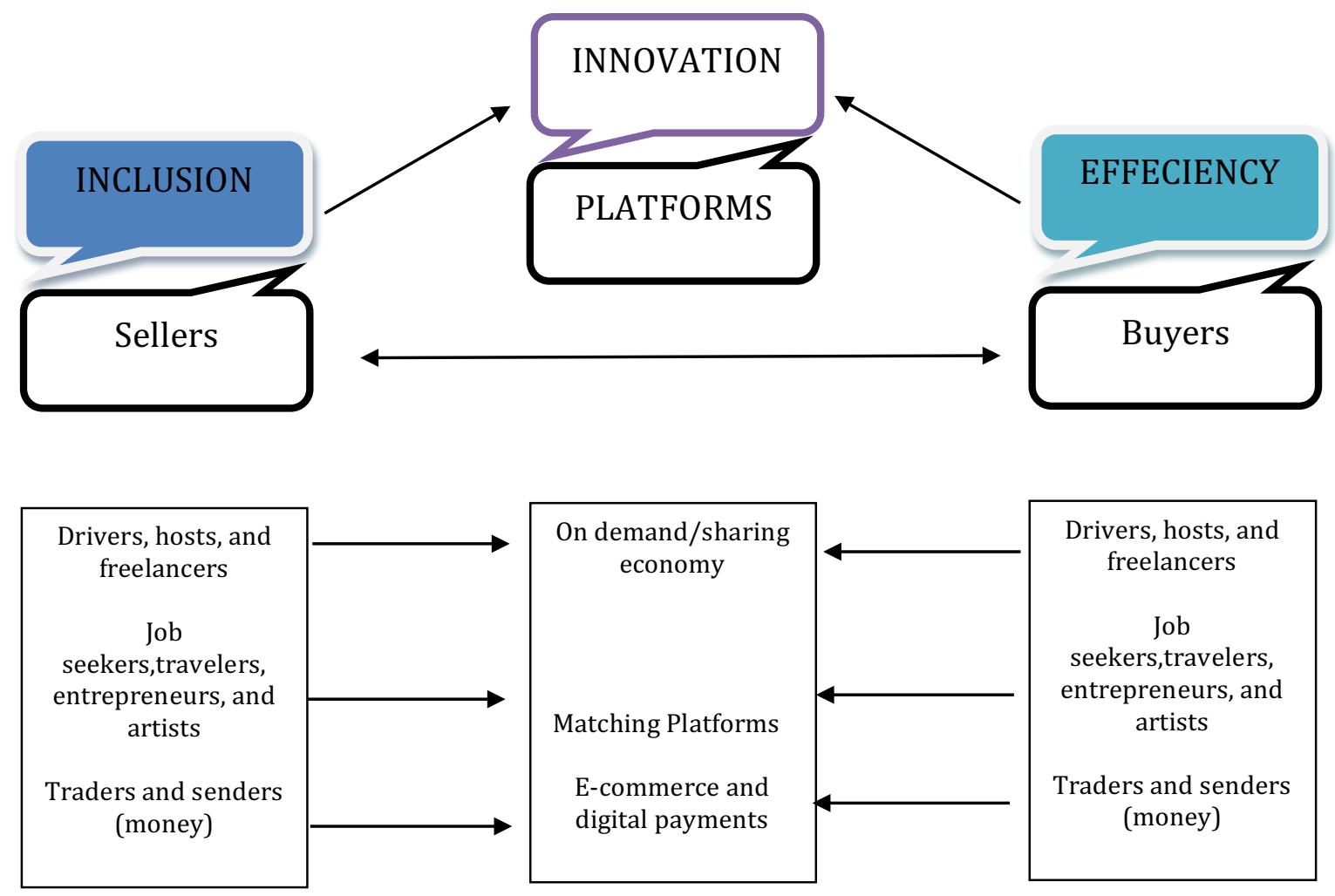


The biggest potential of ICT-based SMEs lies in the domain of e-commerce. It is reported to be the fastest grower and contributor to the ICT industry, hosting an estimated global market volume \$22 trillion (Iftikhar, 2017). It includes all major online stores and shopping marketplaces such as Alibaba, OLX and eBay as well as ICT facilitated services such as Careem and Uber. In Pakistan, online stores such as Daraz and Kamyu have also been registering phenomenal growth. The potential for these services can be gauged with the fact that OLX alone has 500,000+ visitors everyday and Careem has planned to accommodate employment for 100,000 unemployed youth in its next three years. The list below shows top 10 e-commerce sites of Pakistan according to number of unique visitors per month.

\begin{tabular}{|l|l|}
\hline Online Vendors & Website Visits \\
\hline www.daraz.pk & 9.3 million \\
\hline www.kaymu.pk & 1.1 million \\
\hline www.homeshopping.pk & 0.88 million \\
\hline www.symbios.pk & 0.57 million \\
\hline www.shophive.com & 0.48 million \\
\hline www.yayvo.com & 0.46 million \\
\hline www.ishopping.pk & 0.43 million \\
\hline www.mega.pk & 0.39 million \\
\hline www.telemart.pk & 0.27 million \\
\hline www.24hours.pk & 0.21 million \\
\hline
\end{tabular}

Source: Alexa Ranks

\section{Potential for Exports}

Though Pakistan is not a leading export of IT products, the potential of SME sector presents a great promise (Ahmed, Shahzad \& Umar, 2010). According to Pakistan Software Exports Board, major consumption zones for IT products and services of Pakistan include world's most technologically advanced countries, including US, UK, China and Canada. The figure below shows the percentage export shares to each of these zones.

\section{PAKISTANI IT SECTOR MAJOR EXPORT ZONES}

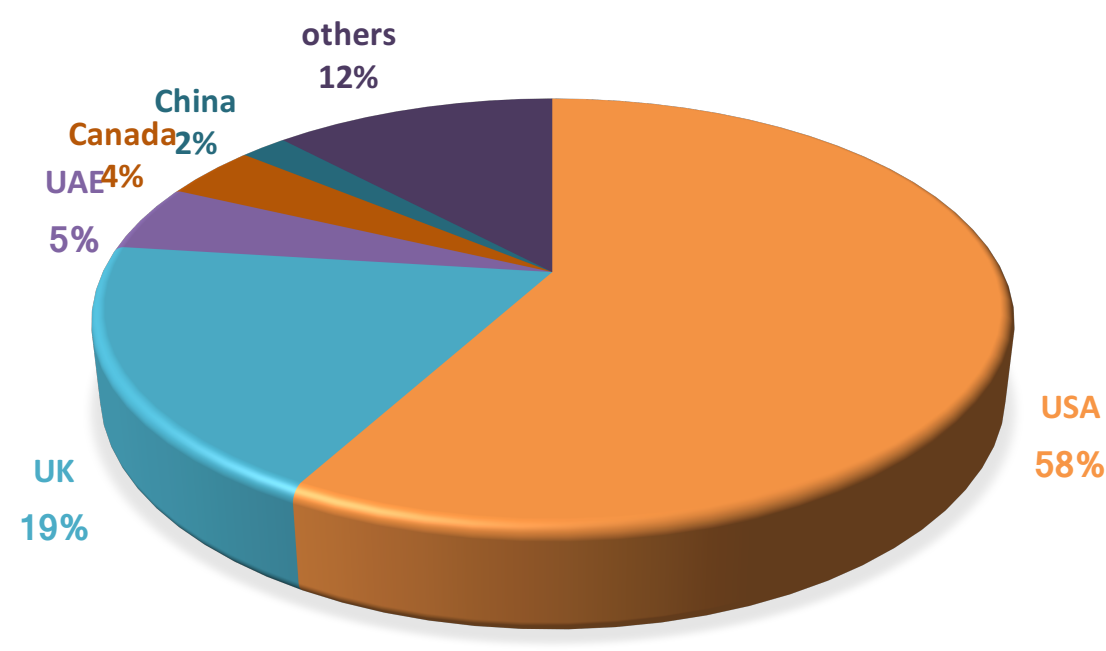

Source: Pakistan Software Exports Board 
The focal organization of SMEs in Pakistan, SMEDA, has already launched an e-Market initiative as part of its strategy to increase exports of the country. The initiative, called Virtual Exchange, is set to provide over 50,000 business leads to exporters of Pakistan, giving them access to 202 territories and countries around the globe (Mujahid 2001). However, SMEDA does not have a specified export cluster for ICT-specific products and services, and hence this SME sub-sector is largely not accounted for in its policy initiatives (Dasanayaka, 2010).

\section{Policy initiatives}

Pakistan has from time to time developed various policy instruments for the promotion of SME sector (SMEDA, 2017). The central bank of the country, SBP; the Small and Medium Enterprises Development Authority, SMEDA; the Security and Exchange Commission of Pakistan, SECP, Pakistan Software Houses Association the Ministry of Information Technology (MOiT) and various provincial schemes such as Prime Minister Youth Business Loans (PMYBL) and eRozgar Scheme have been launched to tap on the potential of ICT SMEs of the country (SMEDA, 2017). Following are the major steps taken by these stakeholders in order to promote the SME sector:

1. SBP has envisioned itself to increase its SME credit outreach to 300,000 SMEs by year 2020. SBP also launched credit guarantee scheme in 2010 for covering up to $40 \%$ credit losses incurred in small businesses. However, SBP is yet to add up service sector SME clusters and business profiles in its credit strategies.

2. SMEDA, through appointment by SBP and PMYBL, has developed 55 small business feasibilities to be used as reference models by banks and loan beneficiaries. However, SMEDA also is not specific for service sector SME clusters.

3. Pakistan Software Export Board (PSEB) has allocated 700,000 square feet of space for registered IT companies through development for various IT facilities, IT parks and software technology parks. It has envisioned itself to double the volume of Pakistan's IT sector by $\$ 5$ billion by 2020 .

4. PMYBL is offering soft loans of up to Rs.2 million, to youth aged 21-45, at a nominal interest rate of $6.0 \%$.

5. More than 300 member software houses have been given ISO certifications through support from Pakistan Software Houses Association.

The continuous expansion and growth of Pakistan's ICT sector demands that policy measures are revised from time to time. A good step in this regard is the introduction of National Digital Pakistan Policy. It heavily accounts for the increasing role of the ICT sector in various domains of our economy, and proposes steps for accelerated digitization of businesses. The policy assumes this multi-stakeholder model so as to ensure a fast track for the sector's growth. It proposes initiatives for empowering governance, accessibility, entrepreneurship, demand stimulation and knowledge capital of the country.

\section{CONCLUSIONS}

With thousands of small IT enterprises and millions of internet and mobile phone users, the ICT sector of Pakistan holds an enormous economic potential for the country in terms of growing employment and consumption opportunities and an even greater room for exports, foreign direct investment and foreign exchange. This vast potential is witnessed in the fact that about seventy percent of our population uses one of the three mediums of electronic communication (landline, fixed or mobile) and the software exports of Pakistan are continuously increasing, with growth in past three years as much as 70 percent and IT exports volume in excess of $\$ 2.5$ billion. In addition, Pakistan stood as the fourth top preferred region for freelance development (Ministry of Information Technology, 2017). 
A plausible way to tap the potential of Pakistan's ICT SME sector is to address its challenges, common of which include non-classification of the sector as an SME subset, creation and retention of the right talent pool for the sector, keeping up with fast-pace of global technologies and easing up of market access limits imposed by IT firms and enablers outside the country, including non-availability of online payment systems such as PayPal, and provision of financing facilities under employment schemes run by the government.

Based on our findings, we recommend that adequate policy measures and initiatives are taken by SME stakeholders like Small and Medium Enterprises Development Authority and State Bank of Pakistan. The institutions are yet to classify ICT based SMEs as their subset which makes them go unsupervised as well as unsupported. Further research can target how ICT sector's policies are in line with policies of the SME sector. The vast potential of the sector can only be untapped when a coherent support system is at place by all stakeholders.

\section{References}

Abor, J. and Quartey, P. (2010). "Issues in SME Development in Ghana and South Africa", International Research Journal of Finance and Economics, 39, pp. 218-228

Ahmed I., Shahzad A., Umar M. (2010) Information Technology and SMEs in Pakistan, International Business Research Vol. 3, No. 4; October 2010 available at www.ccsenet.org/ibr

Alina Anas (2017) Digital Trends Pakistan: Industry Trends Report. Retrieved from www.thedigitz.com

Audretsch, David B. (2000). "The Economic Role of Small and Medium-Sized Enterprises", The United States

Cunningham. L.X. \&Rowlew, C. (2008) "The development of Chinese small and medium enterprises and human resource management: A review. Asia Pacific Journal of Human Resources. 46 (3), 353-379

Dasanayaka W.S.B. (2010) Development of SMEs through clusters: a comparative study of India, Pakistan and Sri Lanka, World Review of Entrepreneurship, Management and Sust. Development, Vol. 6, Nos. 1/2, 2010

Feeny, L.S. and Riding A.L. (1997) “Business Owners' Fundamental Tradeoff: Finance and the Vicious Circle of Growth and Control", Canadian Business Owner, November.

Hameed, T. (n.d.) ICT as an enabler of socio-economic development. [Online]. Available: http://www.itu.int/osg/spu/digitalbridges/materials/hameed-paper.pdf

ITU (2016) A review of Micro, Small and Medium Enterprises in the ICT Sector 2016, published by International Telecommunication Union, Retrieved from https://www.itu.int/dms pub/itus/oth/06/36/S06360000013301PDFE.pdf

Kwarteng, F., Yao, L., Aboagye, O., \&Boatemaa, A. (2016). Institutional Financial Support and SMEs Growth. A Case Study on Selected SMEs in Ghana. British Journal of Economics, Management \& Trade, 12(2), 1-19. doi:10.9734/bjemt/2016/23456

Liedholm, C. and Mead D. (1987). "Small Scale Industries in Developing Countries: Empirical Evidence and Policy Implications", International Development Paper, No. 9., Department of Agriculture Economics , Michigan State University, East Lansing, MI, USA.

Lipton, M. and Ravallion, M. (1995). "Poverty and Policy”, In Behrman, J., Srinivasan, T.N. (eds), Handbook of Development Economics, Vol. IIIB, Amsterdam: Elservier Science B.V., pp. 2551-2657

Madiha Shafique Dar, Shakoor Ahmed and Abdul Raziq (2017) "Small and Medium-Size Enterprises in Pakistan: Definition and Critical Issues" Pakistan Business Review

Ministry of Information Technology (2017) Digital Pakistan Policy 2017 Retrieved from http://moit.gov.pk/policies/DPP-2017v5.pdf

Mujahid, Y. H. (2001) Digital Opportunity Initiative: For Pakistan: A paper evaluating Pakistani eReadiness Initiatives. National Post Graduate Institute of Telecommunications \& Informatics, PTCL IT\&Telecom Division, Ministry of Science \& Technology

Mukras, M.S. (2003). "Poverty Reduction Through Strengthening Small and Medium Enterprises", Botswana Journal of African Studies, 17(2), pp. 58-69 
Naved Hamid (2008) Rethinking Pakistan's Development Strategy, MPRA Paper No. 13491, Lahore School of Economics available at http://mpra.ub.uni-muenchen.de/13491/

P@sha (2017) Facts and Figures Retrieved from http://pasha.org.pk/ict-industry/facts-figures/ on 28 September 2017

Pakistan Software Export Board PSEB (2017) 'PSEB Aims and Objectives' Retrieved from http://www.pseb.org.pk/about-us/aims-and-objectives

Punjab Information and Technology Board PITB (2017) 'e-Rozgar: Program Vision and Objectives' Retrieved from https://www.erozgaar.pitb.gov.pk/about_us

Rahman M., Stough, R. and Jalees, J. (2015) The Effectiveness of Support Policies for SMES in Pakistan: A Study of Karachi Based SMES.PAKISTAN BUSINESS REVIEW. Pp 829-857 Retrieved from http://www.pbr.iobm.edu.pk/wpcontent/uploads/2016/01/1-Mustaghis.pdf

Shafique, F. and Mahmood, K. (2008), Indicators of the Emerging Information Society in Pakistan, Journal of Information Development,Volume 24: 66

Smallbone, D., Leig, R., North, D. 1995: "The Characteristics and Strategies of High Growth SMEs", International Journal of Entrepreneurial Behaviour \& Research, Vol. 1 No.3.

SMEDA (2011) SME Definitions. Retrieved from www.smeda.org.pk on September 28, 2017

SMEDA (2017) Handbook on initiatives for SME promotion and Development Retrieved from https://www.smeda.org/files/State_Bank_Handbook/Handbook_on_Initiatives_for_SME_Promotion_and_Develop ment_by_SBP_SMEDA.pdf

Tsai, C.-J., Sengupta, S., Edwards, P. 2007:"When and Why is Small Beautiful? The Experience of Work in the Small Firm", Human Relations, Vol. 60.

Wadood, F., Dr. Shamsuddin A. and Dr. Abdullah, H, N. (2013) Characteristics of Innovative SMEs in Pakistan: A Case Study, IOSR Journal of Business and Management (IOSR-JBM)Volume 14, Issue 6 (Nov. - Dec. 2013), PP 45-51 